\title{
ANGKUTAN SEDIMEN SUNGAI SIAK DISEKITAR PILAR JEMBATAN SIAK I
}

\author{
Risenal Nick Siregar Sormin ${ }^{1}$, Virgo Trisep Haris ${ }^{2}$, Fitridawati Soehardi ${ }^{3)^{*}}$ \\ ${ }^{1,2,3}$ Program Studi S1 Teknik Sipil, Fakultas Teknik, Universitas Lancang Kuning \\ Jl. Yos Sudarso Km 8 Pekanbaru. \\ Email : $\underline{1}$ rise17sir@gmail.com,${ }^{2}$ virgotrisepharis@gmail.com ${ }^{3}$ fitridawati@unilak.ac.id
}

\begin{abstract}
ABSTRAK
Sungai Siak merupakan salah satu sungai primer di provinsi Riau sehingga sungai ini menampung dan mengalirkan limpasan air dari daerah kiri dan kanan yang ada disepanjang aliran sungai. Sebagai akibat dari perubahan debit angkutan sedimen mengakibatkan terjadinya degradasi di dasar sungai siak sehingga runtuhnya jembatan. Kekhawatiran akibat dari runtuhnya beberapa jembatan diatas sungai siak dan melihat kondisi jembatan siak I perlu dilakukan perhitungan berapa besarkah angkutan sedimen sungai siak disekitar pilar jembatan siak I. Metode yang digunakan untuk menganalisis data menggunakan metode Yang's dan konsep hidraulika, berdasarkan hasil analisis dan perhitungan angkutan sedimentasi akibat debit maksimum menghasilkan angkutan sedimen terbesar yaitu sebesar 3.753,25924 kg/hari.
\end{abstract}

Kata kunci: Angkutan sedimen, Degradasi, Sungai siak, Tegangan geser

\section{ABSTRACT}

Siak River is one of the primary rivers in Riau province, so that this river holds and flows water runoff from the left and right areas along the river flow. As a result of changes in sediment transport discharges resulted in degradation in the riverbed of Siak, resulting in the collapse of the bridge. Concerns due to the collapse of several bridges over the Siak River and seeing the condition of the Siak Bridge I need to calculate how much the sediment river sediment transport is around the Siak bridge pillar. The method used to analyze the data uses the Yang's method and hydraulic concept, based on the results of the analysis and calculation of sedimentation transport due to maximum discharge, the largest sediment transport is 3,753,25924 kg / day.

Keywords: Sediment transport, Degradation, Siak River, Shear stres

\section{PENDAHULUAN}

Jembatan Siak I yang dikenal oleh masyarakat luas dengan nama Jembatan Leighton 1 adalah nama sebuah jembatan yang berlokasi di Kota Pekanbaru, Provinsi Riau, Indonesia. Jembatan Siak I ini menghubungkan dua kecamatan di Kota Pekanbaru yang dipisahkan oleh Sungai Siak, yakni Kecamatan Senapelan yang terletak di sisi Selatan dan Kecamatan Rumbai di sisi Utara.

Jembatan yang berdiri diatas sungai Siak ini diresmikan pada tanggal 19 April 1977 oleh Soeharto yang menjabat sebagai Presiden Republik Indonesia ke 2 saat itu, jembatan ini direncanakan dapat bertahan selama 50 tahun. Namun akibat pemakaian yang meningkat seiring perkembangan Kota Pekanbaru, maka dipasang portal di setiap ujung jembatan untuk membatasi muatan kendaraan yang melaluijembatan tersebut.

Sungai Siak merupakan salah satu sungai primer sehingga sungai ini menampung dan mengalirkan limpasan air dari daerah kiri dan kanan yang ada disepanjang aliran sungai. Meningkatnya penambahan jumlah penduduk dan aktivitas manusia di sepanjang aliran Sungai Siak khususnya Sungai Siak di Kecamatan Rumbai telah memberi pengaruh terhadap ekosistem perairan dan sedimentasi di sungai siak. Besarnya debit angkutan sedimen terutama tergantung dari pada perubahan kecepatan aliran, karena perubahan musim hujan, kemarau, dan aktivitas manusia. Sebagai akibat dari perubahan debit angkutan sedimen adalah terjadinya degradasi dibeberapa tempat serta terjadinya agradasi di tempat lain pada dasar sungai, dengan demikian umumnya bentuk dari dasar sungai akan selalu berubah.

Degradasi dasar sungai merupakan salah satu faktor yang menyebabkan terjadinya kerusakan pada bangunan sungai. Degradasi ini terjadi karena perubahan kecepatan, debit, waktu serta angkutan sedimen pada sungai[1]. Makin lama terjadinya limpasan air dan makin besar debit aliran, maka makin besar degradasi yang terjadi. Apabila degradasi berlangsung secara terus menerus hingga tercapainya keseimbangan antara suplai dengan angkutan sedimen yang saling memperbaiki[2], maka terjadi ketidakseimbangan karena jumlah 
angkutan sedimen lebih besar dari pada suplai sedimenya. Semakin dalamnya lubang gerusan (scour hole) pada pondasi jembatan hal ini dapat menyebabkan terjadinya kerusakan pada jembatan.

Kejadian runtuh nya beberapa jembatan di sepanjang sungai Siak Provinsi Riau: jembatan reteh di Kabupaten Indragiri Hilir, jembatan penghubung Kuansing - Pekanbaru, dan jembatan penghubung Desa Munsalo Kopah Indragiri Hulu disebabkan oleh luapan air sungai siak yang tinggi dikarenakan tidak mampu menampung air hujan yang turun diwilayah sekitar sungai siak mengakibatkan terjadinya gerusan yang besar disekitar pilar jembatan [3][4]sehingga mengakibatkan runtuh nya jembatan-jembatan tersebut dan kemudian melihat kondisi dan mengingat umur rencana jembatan siak I yang hampir mencapai 50 tahun $(1977$ - 2020).

Kekhawatiran akibat dari runtuh nya beberapa jembatan diatas sungai Siak di Provinsi Riau dan melihat kondisi Jembatan Siak I, maka Penulis melakukan Penelitian yang bertujuan untuk mengetahui berapa besar angkutan sedimen sungai siak disekitar pilar jembatan siak I.

\section{Angkutan sedimen}

Sedimentasi adalah proses pengendapan material yang terangkut dan terbawa oleh aliran air dari bagian hulu sungai akibat dari erosi. Sedimen dapat berada di berbagai lokasi dalam aliran, tergantung pada keseimbangan antara kecepatan ke atas pada partikel (gaya tarik dan gaya angkat) dan kecepatan pengendapan partikel[5][6].

Jenis - jenis sedimen

Adapun jenis-jenis sedimen antara lain[7]:

1. Bed load transport

Bed load adalah jenis partikel kasar yang berada di sepanjang dasar sungai secara keseluruhan. Adanya gerakan bergeser, menggelinding atau meloncat-loncat oleh gerekan partikel dengan ukuran cukup besar, hal ini menunjukkan terjadinya gerakan Bed load, namun pergerakan terjadi di dasar sungai.

2. Was load transport

Wash load merupakan angkutan partikel halus yang mempunyai kandungan lempung (silk) dan debu (dust), partikel ini bergerak dan terbawa oleh aliran sungai. Partikel ini akan terus bergerak dan terbawa aliran menuju ke laut, namun tidak semua partikel akan terbawa, sebahagian partikel akan mengendap pada aliran yang lebih tenang atau pada kondisi air yang tergenang.

3. Suspended load transport

Suspended load merupakan material yang sangat halus dan melayang serta mengambang pada aliran air sungai, hal ini diakibat proses dorongan dari turbulensi aliran. Fall velocity atau kecepatan jatuh mempunyai andil yang cukup besar terhadap proses Suspended load

Pada kenyataannya tiap satu satuan waktu pergerakan angkutan sedimen yang dapat diamati hanyalah Bed Load Transport dan Suspended Load Transport.

\section{Sungai}

Sungai merupakan sekumpulan air dengan kapasitas besar yang menciptakan suatu aliran alami dari tempat yang tinggi (hulu) menuju ke tempat yang paling rendah (muara) dengan dibatasi pada kanan dan kirinya serta sepanjang pengalirannya oleh garis sempadan[8][9].

menurut Maryono (2003) menyebutkan bahwa sungai memiliki aliran yang luas dan lengkap tetapi dengan pengamatan dan penelitian jangka waktu yang panjang, sungai dapat diartikan sebagai sistem yang teratur yaitu bahwa semua jenis komponen penyusun sungai adalah sistem yang teratur atau dapat diprediksi. Sistem sungai merupakan sistem yang teratur dan kompleks yang saling memengaruhi satu sama lain terhadap setiap komponennya. Komponen penyusun sungai yaitu bentuk alur dan percabangan sungai, morfologi sungai (river morphology), formasi sungai (river bed form), dan ekosistem sungai (river ecosystem). Jenis material sungai, vegetasi di sekitar sungai, kemiringan memanjang bentang alam memengaruhi bentuk meander[10].

\section{Alur sungai}

Ada tiga bagian alur sungai, diantaranya:

1. Bagian Hulu

Bagian hulu atau sering disebut dengan kepala sungai yaitu suatu bagian dari sungai yang terletak sangat jauh dari muara sungai, bagian ini mempunyai kemiringan lereng yang besar lebih dari $15 \%$, sehingga hulu menjadi daerah yang rentan mengalami erosi. Pada bagian hulu memiliki kecepatan aliran yang lebih besar dari pada bagian hilir, sehingga pada alur ini saat terjadi banjir tidak hanya partikel sedimen halus saja yang terangkut akan tetapi juga pasir, kerikil bahkan batu.

2. Bagian tengah

Bagian tengah adalah daerah perlintasan bagian hulu dan hilir. Pada bagian ini terjadi kemiringan dasar sungai yang landai sehingga kecepatan aliran lebih kecil daripada bagian hulu. Selain itu, bagian ini merupakan daerah keseimbangan proses sedimentasi dan proses erosi yang sangat beragam.

3. Bagian hilir

Bagian hilir atau yang sering disebut dengan muara adalah bagian terakhir dari aliran sungai, Kecepatan aliran pada bagian ini sangat lambat karena melalui dataran yang mempunyai 
kemiringan yang sangat landai. Ini merupakan penyebab dari terjadinya banjir disekitar hilir dan terjadi sedimentasi. Sedimen yang terbentuk berupa endapan pasir halus, endapan organik, lumpur.

\section{METODE PENELITIAN}

\section{Lokasi Pengumpulan Data}

Dalam penelitian Angkutan Sedimen dan Potensi Degradasi pada pilar Jembatan Siak I ini, lokasi penelitian yang dituju untuk mendukung pengambilan informasi dan data adalah Jembatan Siak I yang membentang diatas Sungai Siak I yaitu Jembatan yang berdiri diantara Kecamatan Senapelan dan Kecamatan Rumbai Kota Pekanbaru.

\section{Bahan dan alat penelitian}

Adapun bahan yang dipergunakan dalam penelitian ini adalah sampel air sungai siak yang diambil untuk mengumpulkan informasi. Sedangkan alat yang digunakan adalah meteran sebagai alat ukur, saringan, bak ukur untuk menampung sampel air, current meter, timbangan elektrik (mettler toledo), kalkulator, kamera untuk dokumentasi, kertas catatan beserta alat tulis untuk mencatat hasil penelitian dan komputer untuk menyusun dan mengolah data penelitian.

\section{Teknik pengumpulan data}

Dalam proses pengumpulan data pada penelitian ini dengan mengumpulkan data hidraulik meliputi debit dan cross section dan long profile Sungai Siak pada ruas yang diteliti yaitu Sungai Siak disekitar pilar jembatan Siak I. Data yang diperoleh diambil debit tahunan maksimum yang terjadi pada sungai siak dalam kurun 10 tahun terakhir. Selain itu dibutuhkan sampel sedimen Sungai Siak. Lokasi pengambilan sampel sedimen melayang (Suspended load) sebanyak 3 titik lokasi, yaitu pada kedua ujung lebar sungai dan pada bagian tengah sungai dan data cross section dari BPSDA Pekanbaru. Secara keseluruhan data-data yang diperlukan dalah sebagai berikut:

Tabel 3.1 Debit Air Sungai Siak tahun 2010-2019

\begin{tabular}{|c|c|c|}
\hline \multirow{2}{*}{ Tahun } & \multicolumn{2}{|c|}{ Debit (m3/det) } \\
\cline { 2 - 3 } & Terbesar & Terkecil \\
\hline 2010 & 177,01 & 13,74 \\
\hline 2011 & 209,40 & 8,40 \\
\hline 2012 & 150,20 & 9,36 \\
\hline 2013 & 193,30 & 11,09 \\
\hline 2014 & 201,50 & 12,77 \\
\hline
\end{tabular}

\begin{tabular}{|l|l|l|}
\hline 2015 & 188,60 & 16,40 \\
\hline 2016 & 177,00 & 12,80 \\
\hline 2017 & 164,71 & 10,35 \\
\hline 2018 & 169,78 & 11,85 \\
\hline 2019 & 153,45 & 11,38 \\
\hline
\end{tabular}

\begin{tabular}{|c|c|}
\hline Lebar Sungai Siak & $=79 \mathrm{~m}$ \\
\hline Kedalaman Sungai Siak & $=25 \mathrm{~m}$ \\
\hline \multicolumn{2}{|c|}{ (Sumber: BPSDA Pekanbaru 2020) }
\end{tabular}

\section{Metode Analisis Data}

Langkah - langkah menghitung angkutan sedimen disekitar pilar jembatan Siak I Kecamatan Rumbai adalah sebagai berikut:

1. Menghitung kecepatan aliran air Sungai Siak menggunakan current meter.

2. Menghitung muatan sedimen kasarpada dasar Sungai Siak.

3. Menghitung muatan sedimen melayang pada air Sungai Siak.

4. Menghitung angkutan sedimen dengan memakai Metode Yang's.

\section{Bagan Alir Penelitian}

Secara keseluruhan proses penghitungan angkutan sedimentasi sungai siak disekitar pilar jembatan siak I di Kecamatan Rumbai ini dapat dilihat dalam bagan alir dibawah:

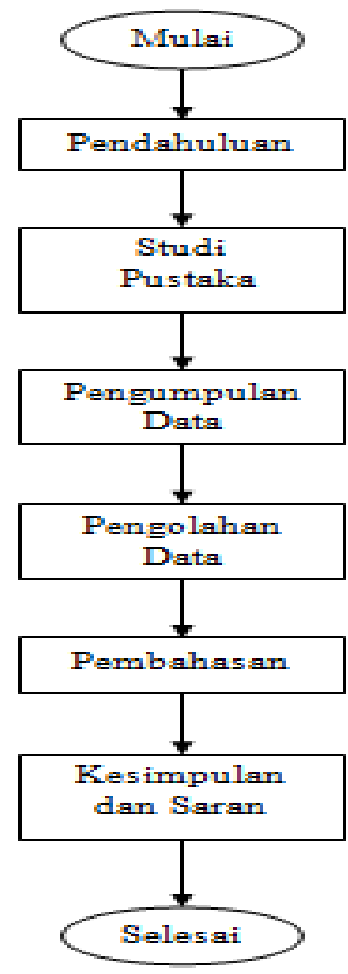


Gambar 3.2 Bagan alir penelitian

\section{HASIL DAN PEMBAHASAN}

\section{Metode Yang's}

Untuk mengetahui berapa besar angkutan sedimen yang terjadi pada sungai siak khususnya disekitar pilar jembatan siak I, maka dilakukan perhitungan dengan menggunakan metode Yang's (1973), karena Perhitungan Yang mendasarkan pada perhitungan Bed Load dan Suspended Load yaitu, parameter unit stream power (satuan daya aliran) yang akan menjadi parameter dalam menyusun persamaan empiris. Dalam langkahnya juga menetapkan adanya satuan daya kritis yang sebagai transisi antara proses pengendapan dan angkutan sedimen, berikut langkah - langkah perhitungan Bed Load dan perhitungan Suspended Load:

1. Perhitungan Bed Load:

$$
\begin{aligned}
& A=(B+m \cdot H) \cdot H \\
& =(79+2 \cdot 25) \cdot 25 \\
& =\quad 3225 \mathrm{~m}^{2} \\
& P \quad=\quad B+2 \cdot H \sqrt{1+m^{2}} \\
& =79+2 \cdot 25 \sqrt{1+2^{2}} \\
& =190,803398 \mathrm{~m} \\
& R=\frac{A}{P} \\
& =\frac{3225}{190,803398} \\
& =\quad 16,902214 \mathrm{~m} \\
& V \quad=\quad \frac{Q}{A} \\
& \begin{array}{l}
=\frac{209,40}{3225} \\
=\quad 0,0649 \mathrm{~m} / \mathrm{dt}
\end{array}
\end{aligned}
$$

Masukkan nilai yang didapat kedalam rumus mannning untuk mencari nilai $I$

$$
\begin{aligned}
& V \quad=\quad \frac{1}{n}(R)^{\frac{2}{3}}(I)^{\frac{1}{2}} \\
& 0,0649=\frac{1}{0,030}(16,902214)^{\frac{2}{3}}(I)^{\frac{1}{2}} \\
& I^{\frac{1}{2}}=0,012823 \\
& \begin{array}{rll}
I & = & 0,012823^{2} \\
& = & 0,000164
\end{array}
\end{aligned}
$$

$$
\begin{aligned}
& \omega=\frac{1}{18} \cdot \frac{\gamma s-\gamma w}{\gamma w} \cdot g \cdot \frac{D_{50}{ }^{2}}{u} \\
& =\quad \frac{1}{18} \cdot \frac{2714-1000}{1000} \cdot 9,81 \cdot \frac{0,00147^{2}}{1,25 \cdot 10^{-6}} \\
& =\quad 1,614849 \mathrm{~m} / \mathrm{dt} \\
& U_{*} \quad=\quad \sqrt{g \cdot R \cdot S} \\
& =\sqrt{9,81 \cdot 16,902214 \cdot 0,0001} \\
& =0,128767 \mathrm{~m} / \mathrm{dt} \\
& V_{c r}=\left[\frac{2,5}{\log \left(\frac{U_{*} \cdot D_{50}}{\vartheta}\right)-0,06}+0,66\right] \cdot \omega
\end{aligned}
$$$$
\left.\begin{array}{l}
=\left[\frac{2,5}{\log \left(\frac{0,128767 \cdot 0,00147}{1,25 \times 10^{-6}}\right)-0,06}+0,66\right. \\
2,969913 \mathrm{~m} / \mathrm{dt}
\end{array}\right] \cdot 1,614849
$$

$M_{1}$

$$
\begin{aligned}
& 5,435-0,286 \log \left[\frac{\omega \cdot D_{50}}{\vartheta}\right]-0,457 \log \left[\frac{U_{*}}{\omega}\right] \\
& =5,435-0,286 \log \left[\frac{0,422850 \cdot 0,00147}{1,25 \times 10^{-6}}\right]- \\
& 0,457 \log \left[\frac{0,128767}{1,614849}\right] \\
& =\quad 5,165709
\end{aligned}
$$

$N_{1}$

$$
1,799-0,409 \log \left[\frac{\omega \cdot D_{50}}{\vartheta}\right]-0,314 \log \left[\frac{U_{*}}{\omega}\right]
$$$$
1,799-0,409 \log \left[\frac{0,422850 \cdot 0,00147}{1,25 \times 10^{-6}}\right]-
$$$$
0,314 \log \left[\frac{0,128767}{1,641849}\right]
$$

$$
=\quad 1,043229186
$$




$$
\begin{aligned}
& \log C_{t}=\quad M_{1}+N_{1} \log \left[\frac{V \cdot S}{\omega}-\frac{V_{c r} \cdot S}{\omega}\right] \\
& =\quad 4,983345+0,977769 \mathrm{x} \\
& \log \left[\frac{0,0649 \cdot 0,0001}{1,641849}-\frac{2,969913 \cdot 0,0001}{1,641849}\right] \\
& \begin{array}{ll}
= & 1,314573 \\
C_{l} & =10^{\log C t}
\end{array} \\
& =\quad 10^{1,314573} \\
& =\quad 20,633504 \mathrm{ppm} \\
& =0,206335 \mathrm{~kg} / \mathrm{m}^{3} \\
& q_{s}(\mathrm{dt})=C_{t} \cdot Q \\
& =0,206335 \times 209,40 \\
& =\quad 43.206549 \mathrm{~kg} / \mathrm{dt} \\
& q_{s} \text { (hari) }=43.206549 \times 86400 \\
& =\quad 3.733 .045 \mathrm{~kg} / \mathrm{hari}
\end{aligned}
$$

2. Perhitungan Suspended Load:

$$
\begin{array}{rlll}
q s & = & 0,086 \times C s \times \\
& & = & 0,086 \times 0,011 \times 209,40 \\
& = & 19,80924 \mathrm{~kg} / \mathrm{hari}
\end{array}
$$

Hasil dari perhitungan Bed Load dan perhitungan Suspended Load tersebut digunakan menjadi hasil perhitungan untuk angkutan sedimen pada penelitian ini.

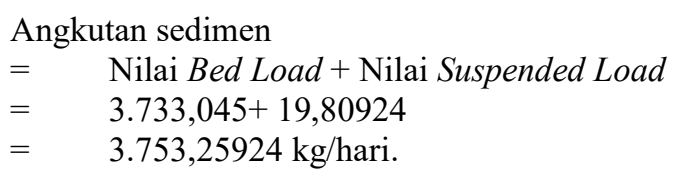

\section{DAFTAR PUSTAKA}

Berdasarkan hasil dari perhitungan analisis pada perhitungan angkutan sedimen didapatkan hasil angkutan sedimen sebesar 3.753,25924 kg/hari.

\section{DAFTAR PUSTAKA}

[1] M. F. Suma, F. Halim, and L. A. Hendratta, "Analisis gerusan lokal pada pilar jembatan kuwil kabupaten minahasa utara menggunakan metode empiris," vol. 6, no.
11, pp. 1017-1028, 2018.

[2] D. A. Hakim, Suyanto, and Solichin, "Analisis Angkutan Sedimen Pada Sungai Bengawan Solo Ruas Serenan-Jurug," Matriks Tek. Sipil, vol. 3, no. 1, pp. 277284, 2015.

[3] J. Ikhsan and W. Hidayat, "Pengaruh bentuk pilar jembatan terhadap potensi gerusan lokal," Ilm. Semesta Tek., vol. 9, no. 2, pp. 124-132, 2006.

[4] A. Amelia, U. Lasminto, and B. Sarwono, "Studi Kapasitas Angkut dan Gerusan Lokal Pada Penampang Sungai Brantas Akibat Pilar Jembatan Tol Mojokerto-Kertosono," J. Tek. ITS, vol. 6, no. 2, pp. 277-283, 2017.

[5] S. Adinegara, "Volume Angkutan Sedimen Dipengaruhi Oleh Kecepatan Aliran Kajian: laboratorium," Media Komun. Tek. Sipil, vol. 13, no. 2, pp. 94-105, 2005.

[6] D. L. Muhammad Iqbal Pratama and A. P. Raharjo, "Analisis Transportasi Sedimen Serta Pengaruh Aktivitas Penambangan Pada Sungai Sombe, Palu, Sulawesi Tengah," Tek. Pengair., vol. 10, no. 2, pp. 84-96, 2019.

[7] R. Sumarto, K. Amri, and M. Fauzi, "Kajian Laju Angkutan Sedimen Total Pada Kantong Lumpur Bendung Air Alas Kabupaten Seluma," in Civil Engineering and Built Environment Conference 2019, 2019, vol. 1, no. 1, pp. 237-245.

[8] H. Pangestu and H. Haki, "Analisis Angkutan Sedimen Total Pada Sungai Dawas Kabupaten Musi Banyuasin," Tek. Sipil dan Lingkung., vol. 1, no. 1, pp. 103109, 2013.

[9] T. Marhendi and A. Imron, "Model Angkutan Sedimen Untuk Analisis Peningkatan Sedimentasi Di Hulu Bendung Gerak Serayu," Techno (Jurnal Fak. Tek. Univ. Muhammadiyah Purwokerto), vol. 21, no. 1, pp. 57-64, 2020.

[10] Reynaldo and W. A. Pranoto, "Kajian Tiga Rumus Angkutan Sedimen Melayang Sungai Serayu Dibandingkan dengan Hasil Laboratorium," Mitra Tek. SIpil, vol. 2, no. 4, pp. 211-220, 2019. 